\title{
Management of Ischaemic Stroke: The Role of the Neurosurgeon
}

\author{
Traitement chirurgical de l'AVC ischémique: Le rôle du neurochirurgien
}

\author{
B. Ogungbo*, D. Okor*, F. I. Ojini ${ }^{\dagger}$
}

\begin{abstract}
BACKGROUND: Neurosurgeons are often not involved in the management of patients with stroke in Nigeria.

OBJECTIVE: To discuss the role of neurosurgeons in the management of ischaemic stroke.

METHODS: We looked at the contributions that a neurosurgeon may be able to make in the care of the patient with an ischaemic stroke. The emphasis was on preventive and curative interventions in the surgical armamentarium of the neurosurgeon that could be of benefit to the patient.

RESULTS: We presented some scenarios in patients with ischemic stroke that may require the assistance of a neurosurgeon. The article explored the role of preventive and definitive surgery in reducing morbidity and mortality in ischaemic stroke patients.

CONCLUSION: There is a role for the neurosurgeon in the management of patients with ischaemic stroke. It is important that patients who might benefit from neurosurgical intervention are referred early for neurosurgical evaluation. WAJM 2010; 29(3): 143-145.
\end{abstract}

Keywords: Neurosurgeon; Ischaemic stroke; Surgical management; Nigeria.

\section{RÉSUMÉ}

CONTEXTE: Les neurochirurgiens sont souvent pas impliquée dans la gestion des patients ayant subi un AVC au Nigeria.

OBJECTIF: Pour discuter du rôle des neurochirurgiens dans le gestion des accidents vasculaires cérébraux ischémiques. METHODES: Nous avons examiné les contributions que le neurochirurgien peut être en mesure de prendre en charge par le patient avec une ischémie accident vasculaire cérébral. L'accent était mis sur les mesures préventives et curatives interventions dans l'arsenal chirurgical de la neurochirurgien qui pourrait être bénéfique pour le patient.

RÉSULTATS: Nous avons présenté certains scénarios chez les patients atteints accident vasculaire cérébral ischémique qui peuvent nécessiter l'assistance d'un neurochirurgien. L'article explore le rôle de prévention et de chirurgie définitive de réduire la morbidité et de mortalité dans ischémique patients victimes d'AVC.

CONCLUSION: Il ya un rôle pour le neurochirurgien dans le gestion des patients ayant un AVC ischémique. Il est important que les patients qui pourraient bénéficier d'une intervention neurochirurgicale sont visés au début de l'évaluation en neurochirurgie. WAJM 2010; 29 (3): 143-145.

Mots-clés: Neurochirurgien; AVC ischémique; chirurgicaux gestion; Nigeria.

\footnotetext{
Departments of *Neurosurgery, Western General Hospital, Edinburgh, Medicine, Lagos University Teaching Hospital, Lagos. Correspondence: Dr Frank I. Ojini, Department of Medicine, College of Medicine, University of Lagos, P.M.B. 12003, Lagos, Nigeria. E-mail: fojini@yahoo.co.uk

Abbreviations: CT, Computerised Tomography; CSF, Cerebrospinal fluid; TIA, Transient ischaemic attack
} 


\section{INTRODUCTION}

Stroke is the third most common cause of death in the Western world and a principal cause of disability. The available data show that prevalence of disabling stroke and case fatality in Africa are similar to or higher than those in most high-income regions. ${ }^{1}$ Stroke is emerging as a leading cause of preventable disability and death in adults in many developing nations. In sub-Saharan Africa, stroke mortality in some countries exceeds those in the developed world. ${ }^{2}$

We have previously reported on cerebrovascular disease in Nigeria. ${ }^{3}$ Available evidence suggests that neurosurgeons are often not involved in the management of patients with ischaemic stroke in Nigeria. Also, in most instances, only neurologists and stroke physicians treat patients with subarachnoid haemorrhage in Nigeria. ${ }^{4}$ However, there is a role for the neurosurgeon to play in the management of patients with stroke. Many patients are suitable for preventive surgical therapy as well as therapeutic procedures aimed at decreasing morbidity and preserving life $^{5}$. The advice of a neurosurgeon early before dramatic and fatal deterioration occurs can be invaluable.

This article reviews the role of a neurosurgeon in the management of patients with cerebral ischaemia, the key point being to remind our physicians of the important role surgery can play in limiting morbidity and reducing mortality. These are discussed under the following headings;

- Brain protection in stroke patients

- Carotid endarterectomy

- Decompressive craniectomy

- Posterior fossa craniectomy for cerebellar infarct; and

- Cerebrospinal fluid diversion and treatment of hydrocephalus

\section{Principles of Brain Protection in Stroke Patients}

The initial management of the stroke patient requires efforts at brain protection to prevent secondary brain injury. This neccesitates due attention to the airway, breathing and circulation. Airway protection and control must be secured as early as possible. Aspiration is a major cause of morbidity and mortality in stroke patients. Breathing and adequate supply of oxygen to the brain must be ensured. Adequate oxygenation of the brain will prevent or ameliorate secondary ischemic insults. The initial management must also include correction of hypertension, hypotension, hyperglycaemia and hyponatraemia. Pyrexia and seizures must also be adequately controlled. Essentially, the general condition of the patient must be normalised as soon as possible and the doctor ready to prevent or manage complicating circumstances as efficiently as practicable.

Brain protection means ensuring adequate supply of nutrients to the brain and prevention of raised intracranial pressure. Sedation with ventilation, if necessary, mannitol and diuretics may be useful in controlling raised intracranial pressure. Raised intracranial pressure is often due to brain oedema which can perpetuate itself in a vicious cycle. The brain swelling and oedema leads to compression of the vasculature which causes more ischaemia and cerebral hypoxia; further worsening the oedema. Heroic efforts are then required to prevent total destruction of the brain. Prevention is somewhat easier.

\section{Carotid Endarterectomy}

The branch point of the common carotid artery is often the setting for deposition of cholesterol plaques leading to varying degrees of blockage of the vessel. Ulceration of the plaques can lead to thrombosis and embolism with subsequent obstruction of intracranial blood vessels. The operation to open the carotid arteries and clean out the plaque is called carotid endarterectomy.

Carotid endarterectomy can be performed under local or general anaesthesia and reduces the risk of stroke in patients who have a mini stroke or transient ischaemic attack (TIA). ${ }^{6}$ Patients with TIA are at increased risk of major ischaemic stroke and require preventive treatment. ${ }^{2}$ Patients who have had a TIA must be evaluated with a carotid ultrasound scan and the degree of stenosis determined. Ogunrin (personal communication, 2009) reported that about $3-7 \%$ of their patients presenting with stroke have carotid stenosis. If more than $70 \%$ stenosis is discovered, such patients should be offered carotid surgery as a semi-emergency procedure. Benefit from the operation depends on the degree of carotid stenosis with some benefit for patients with 50-69\% symptomatic stenosis, and high benefit for those with $70 \%$ symptomatic stenosis or greater but without near-occlusion. ${ }^{7}$

In patients presenting with TIAs, strokes occur most often during the following hours and days later. ${ }^{8}$ Sound clinical evaluation and duplex carotid ultrasound are required to pick up those with carotid stenosis. ${ }^{9}$ Since the therapeutic window is short, such patients may benefit from early referral to a vascular surgeon or neurosurgeon with expertise in carotid endarterectomy. Ideally, the procedure should be done within two weeks of the patient's last symptoms. ${ }^{6}$

Carotid and intracranial blood vessel bypass surgery can also be performed in carefully selected patients with stenosis to reperfuse areas of the brain with reduced blood supply. Conditions such as moya moya, sickle cell disease and carotid trauma may present with cerebral ischaemia. A particular/specific blood vessel is compromised leading to significant reduction in blood flow to the brain. Bypass using the superficial temporal artery (low flow bypass), radial artery or long saphenous vein (high flow bypass) can be performed to restore flow in some patients.

\section{Decompressive Craniectomy}

Major cerebral ischaemia can lead to infarction of a large part of the brain. This area develops oedema which leads to raised intracranial pressure. Because the skull is rigid and unyielding, herniation of the brain occurs with injury to other parts of the brain and the real possibility of death. Decompressive craniectomy is an operation that is of proven benefit in some patients with massive infarctive stroke. Malignant middle cerebral artery syndrome is such a clinical condition and is fatal if not treated appropriately. ${ }^{10}$ 
In the Oxfordshire Community Stroke Project, 53\% of all deaths within 30 days of stroke were due to the direct neurological sequelae of the stroke. ${ }^{11}$ Fifty-six percent of such deaths occurred within 72 hours of onset. Some of those with definitive strokes can be helped with decompressive craniectomy to control intracranial hypertension. Removal of a large part of the skull effectively controls intracranial pressure and has been shown to reduce mortality from $80 \%$ to as low as $10 \% .{ }^{10}$ According to a study, $8(67 \%)$ of 12 patients who underwent hemicraniectomy survived and only $3(25 \%)$ of 12 patients who had maximal medical therapy survived. ${ }^{12}$ Done early, the procedure prevents death especially in young patients, but does not improve the disability due to the initial infarct.

Hemicraniectomy is most promising as a method of avoiding death from brain compression, but optimum timing and patient selection are vital. Surgical hemicraniectomy should be considered in patients with malignant cerebral oedema. Early referral to a neurosurgeon before coma ensues can lead to significant decrease in morbidity and mortality.

\section{Posterior Fossa Craniectomy for Cerebellar Infarct}

In certain situations, a decompressive posterior fossa craniectomy can save lives in patients with massive cerebellar infarction. ${ }^{13}$ In younger patients this operation can be combined with removal of some of the infarcted brain tissue to further reduce the pressure on the brain stem. Urgent neurosurgical care must be made available to selected patients such as those with large cerebellar infarcts, impending brain stem compression and patients with obstructive hydrocephalus. In this regard, there should be close communication and early discussions with the neurosurgeon in patients with depressed level of consciousness.

\section{Cerebrospinal Fluid Diversion and Treatment of Hydrocephalus}

Cerebrospinal fluid (CSF) diversion in patients with stroke can be a simple life saving procedure. Obstruction of the pathway for CSF flow sometimes complicates stroke and can lead to an increase in patient morbidity and mortality. The procedures of CSF diversion are fairly standard and should be considered for patients deteriorating in conscious level due to either communicating or non-communicating hydrocephalus. CSF diversion via an external ventricular drainage system or internalised ventriculo-peritoneal shunts are options to control raised intracranial pressure. The operations have to be done in a timely fashion: before significant neurological deterioration occurs. Treatment of hydrocephalus in patients with stroke needs to be expedient.

\section{Conclusion}

We have presented scenarios in patients with ischemic stroke that may require the assistance of a neurosurgeon. Many neurosurgical interventions may prevent death but do not improve disability or more importantly quality of life. In these regards, a careful balance is required and the ability of the neurosurgeon to select patients who will benefit is important. What is important is that the patients should be referred early for neurosurgical evaluation before irreversible damage has ensued. Apart from early $\mathrm{CT}$ head scan in stroke patients, a repeat scan is required in those who are deteriorating or not improving, to detect complications that might require surgical intervention.

\section{Conflict of Interest Statement}

None of the authors has any conflict of interest to disclose

\section{REFERENCES}

1. Ogun SA, Ojini FI, Ogungbo B, Kolapo KO, Danesi MA. Stroke in south west Nigeria: a 10-year review. Stroke 2005; 36: $1120-1122$.

2. Ogungbo B, Ogun SA, Ushewokunze S, Mendelow AD, Rodgers H, Walker R. How can we improve the management of stroke in Nigeria, Africa? African Journal of Neurological Sciences 2005; 24: 9-19.

3. Ogungbo BI, Gregson B, Mendelow AD, Walker R. Cerebrovascular diseases in Nigeria: what do we know and what do we need to know? Trop Doct 2003; 33: 25-30.
4. Ogungbo B, Mendelow AD, Walker R. The epidemiology, diagnosis and treatment of subarachnoid haemorrhage in Nigeria: what do we know and what do we need to know? $B r J$ Neurosurg 2004; 18: 362-366.

5. Rothwell PM, Mehta Z, Howard SC, Gutnikor SA, Warlow CP. Treating individuals 3: from subgroups to individuals: general principles and the example of carotid endarterectomy. Lancet 2005; 365: 256-265.

6. Gough MJ, Bodenham A, Horrocks M, Colam B, Lewis SC, Rothwell PM, et al. GALA: an international multicentre randomised trial comparing general anaesthesia versus local anaesthesia for carotid surgery. Trials 2008; 9: 28.

7. Rothwell PM, Eliasziw M, Gutnikov SA, Fox AJ, Taylor DW, Mayberg MR, et al; for the Carotid Endarterctomy Trialists' Collaboration. Analysis of pooled data from the randomised controlled trials of endarterectomy for symptomatic carotid stenosis. Lancet 2003; 361: 107-116.

8. Rothwell PM, Warlow CP. Timing of TIAs preceding stroke: time window for prevention is very short. Neurology 2005; 64: 817-820.

9. Hankey GJ, Warlow CP. Symptomatic carotid ischaemic events: safest and most cost effective way of selecting patients for angiography, before carotid endarterectomy. BMJ 1990; 300: $1485-1491$.

10. Chen C, Smith ER, Ogilvy CS, Carter BS. Decompressive craniectomy: physiologic rationale, clinical indications, and surgical considerations. In: Schmidek HH, Roberts DW, editors. Operative neurosurgical techniques: Indications, methods, and results. Vol 1. Philadelphia. Saunders, Elsevier; 2006: p 70-79.

11. Bamford J, Dennis M, Sandercock P, Burn J, Warlow C. The frequency, causes and timing of death within 30 days of a first stroke: the Oxfordshire Community Stroke Project. J Neurol Neurosurg Psychiatry 1990; 53: 824829.

12. Holtkamp M, Buchheim K, Unterberg A, Hoffman O, Schielke E, Weber JR, et al. Hemicraniectomy in elderly patients with space occupying media infarction: Improved survival but poor functional outcome. J Neurol Neurosurg Psychiatry 2001; 70: 226-228.

13. Hornig CR, Rust DS, Busse O, Jauss M, Laun A. Space-occupying cerebellar infarction. Clinical course and prognosis. Stroke 1994; 25: 372-374. 